\title{
Assessment of Vaccination Coverage of Sheep and Goat using Retrospective Data in Woreda Raya Alamata
}

Adhana Tadege and Berihun Afera*

College of Veterinary Medicine, Mekelle University, P.O. Box 231, Mekelle, Ethiopia (*berihun414@yahoo.com/berihun.afera@mu.edu.et).

\begin{abstract}
A retrospective study using data of the record of the veterinary clinic of Alamata Woreda with the objective of assessment vaccine coverage in the area was conducted from May to June 2014. The data indicated that there was vaccination program for ovine pasteurellosis, sheep and goat pox, pestides petites ruminits and anthrax. The vaccination coverage in the area was very minimal and did not cover the whole livestock population. This might be the reason for the reoccurrence of the disease in different years. Hence, use of high quality and effective vaccines to cover a large number of livestock is essential for the disease mitigation in the area.
\end{abstract}

Keywords: Anthrax, Pasteurellosis, Pest ides petites ruminits, Pox vaccine, Alamata, Tigray, Ethiopia.

\section{INTRODUCTION}

Vaccination is widely recognized as one of the most efficient tools of public health, showing obsessions cost-benefit advantages for all the target population involved. Because of the increased movements of people, live animals and food of animal origin partly as a result of the recent WTO agreements- the need to control the risk of disease spread is greatly enhanced. Given that infections do not respect national borders, the need for control of animal infections has become a priority (Pastoret et al., 1996).

Vaccines are employed to include a specific systematic and, or local, humoral and cellular immune response, to initiate or enhance protection of the host against viral, bacterial or parasitic attacks. Immunity generally limits the spread of infection, either by keeping it localized or by restricting its level. And further, it prevents or limits the clinical signs of the disease and as a result eliminates or reduces economic losses associated with the disease, as far as livestock is concerned. Vaccination may also reduce excretion of pathogen by the infected animal, thereby decreasing the risk of its dissemination to other species (Melesse, 2004).

The resources needed for vaccination campaigns include trained man power and adequate finance to provide vehicles and equipment. Unfortunately these are very poor throughout Ethiopia. In many areas particularly in hot areas there is no availability of reliable electric refrigeration and it is difficult to maintain a cold- chain to ensure live vaccine stability both at 
local storage and at the site of vaccination center. Sufficient quantities of ice and insulated boxes must be available for the distribution in the field (Waqnwayi et al., 1997). So far there is no study conducted to assess the vaccination coverage in the area with reference to the total animal population, a study was designed with the objective of assessing the vaccination coverage of the study area.

\section{MATERIALS AND METHODS}

\subsection{Description of the Study Area}

The study was conducted at Alamata Woreda located $600 \mathrm{~km}$ north of Addis Ababa and about 2000-3000 meter above sea level. It is situated between $12^{\circ} 15^{\prime \prime} \mathrm{N}$ and $39^{\circ} 35^{\prime \prime} \mathrm{E}$. The average rain fall ranges from $250-600 \mathrm{~mm}$ and temperature ranges between $17-27^{\circ} \mathrm{C}$ (TBOABR, 1997).

\subsection{Study Design and Sampling Methodology}

Five years (2009 to 2014) retrospective data from the animal's health division, Bureau of Agriculture is used in the present study.

\subsection{Data Analysis}

The data collected from the Bureau reports was recorded on Microsoft excel spread sheet and coded properly and for data analysis descriptive statistics using SPSS version 16 software was used.

\section{RESULTS}

The results indicate that the most important animal diseases occurred in the area are due to ectoparasites such as ticks, mange mites and bacterial diseases namely anthrax, blackleg, CCPP, CBPP, pasteurellosis. In addition, viral diseases such as FMD, PPR, sheep and goat pox and contagious ecthyma are some of the frequently encountered diseases in animals in the Woreda. In addition, there are internal parasite diseases namely lungworm infection, fasciolosis, giardiasis and other helimenth infections. At the same time there is hypocalcaemia in dairy cattle. With regard to vaccination program against the common diseases during the last five years is very minimum. One of the reasons for the recurrence of the diseases may be due to the introduction of infected animals from another area having similar or different serotypes since there is free movement of animals. The vaccination program carried out in the Woreda for different disease 
such as sheep and goat pox, pestides petitis eruminitis, ovine pasteurellosis and anthrax is shown in figures 1 to 4 .

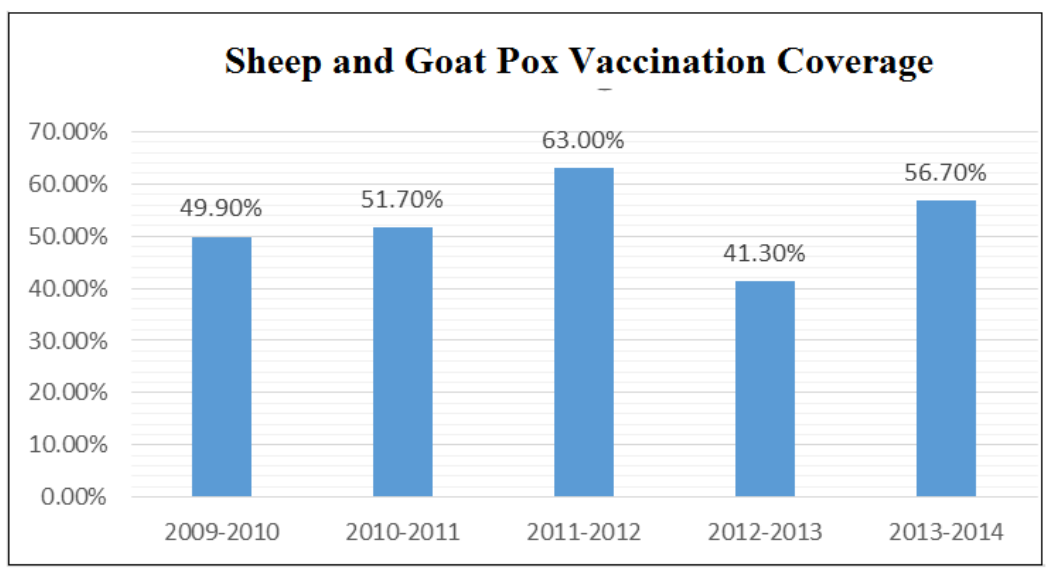

Figure 1. Year-wise Sheep and Goat vaccination coverage in the study area.

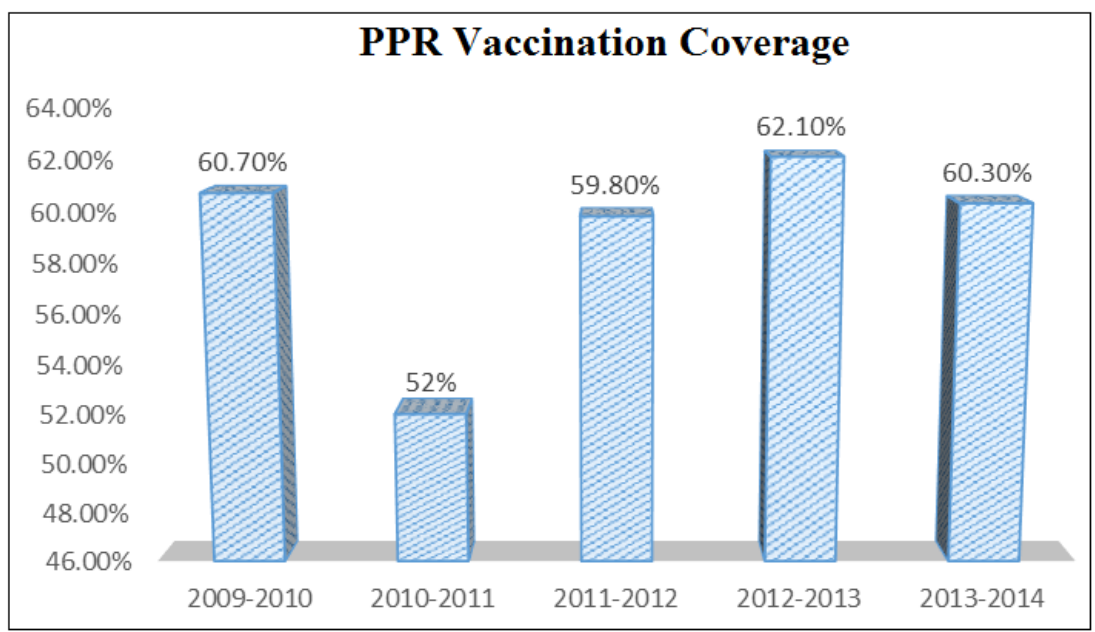

Figure 2. Years-wise pestides petitis ruminitis vaccination coverage in the study area.

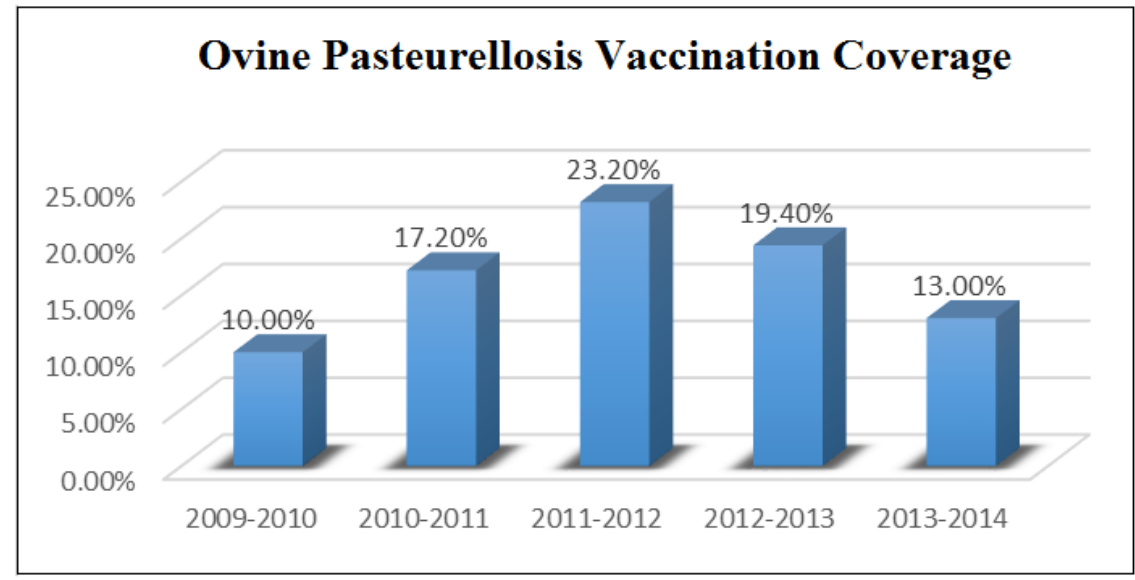

Figure 3. Year-wise ovine Pasteurellosis vaccination coverage in the study area. 


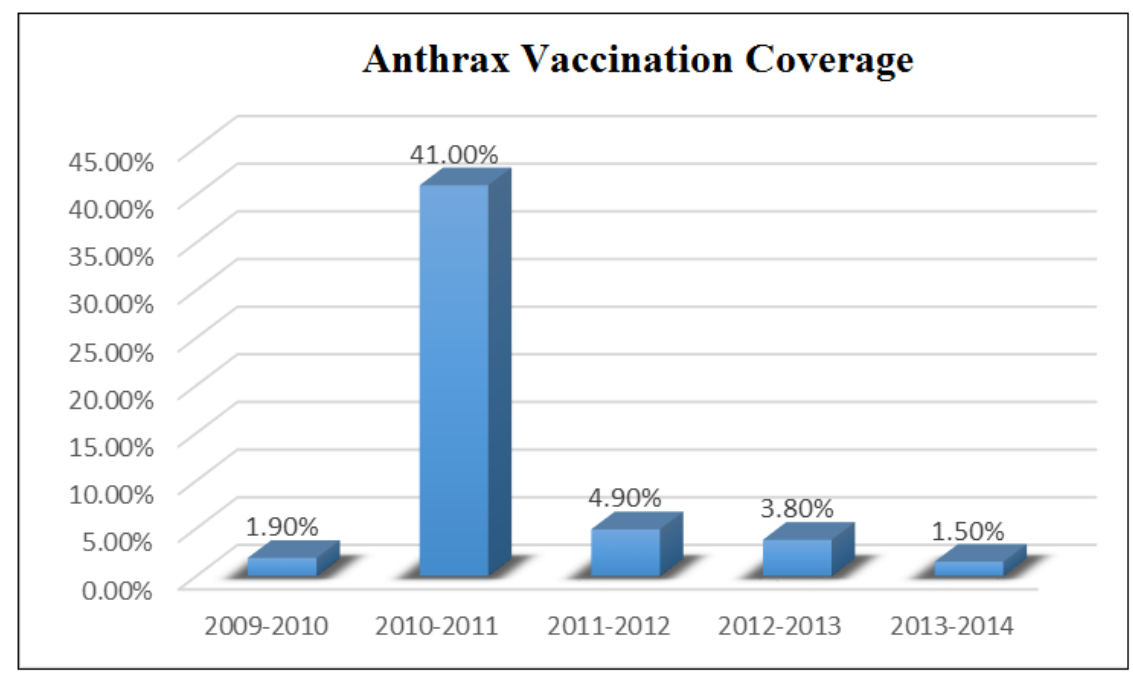

Figure 4. Year-wise anthrax vaccination coverage in the study area.

\section{DISCUSSION}

In the study area, different vaccines were given to small ruminants and large ruminants every year even though the amount of the total livestock vaccines varied from time to time. This vaccination program is essential to protect the animals from different disease. The vaccines included sheep and goat pox vaccines, ovine pasteurellosis vaccine, pestides petites ruminits vaccine and anthrax vaccine.

The strategy of vaccination in the Woreda was annual blanket vaccination and ring vaccination during disease outbreaks. Due to shortage in the supply of vaccines and manpower in the Woreda its coverage was $38.3 \%$ for sheep and Goats population. Due to these limitations, the overall disease prevention and control program in the Woreda was not effective and the effectiveness of the vaccines was impaired.

Though it is indicated that all the animal population for any disease should be vaccinated before the outbreaks for successful vaccination (Melesse, 2004), the data indicate that only limited number of animals was vaccinated. In contrast to the current finding, Teshager et al. (2013) indicated that $83 \%$ of his respondents used traditional treatment rather than treating their animals in veterinary clinic and vaccinated them. In line with the vaccination scheme of the Woreda (NVI, 2004) sheep and goat should be vaccinated 5 times for four diseases namely pasteruellosis, anthrax, sheep pox and PPR per annum. 
Concurrent to the current finding, the MoA (2011) stated that the domestic vaccine consumption ranges between 25 million and 40 million doses according to annual vaccination figures for different years. There is a wide margin, from production view point, to increase the foreign trade of most of the vaccines under production and intensified promotion effort would seem to be beneficial. Technology transfer, especially in the area of vaccine production is becoming imperative as there is already a national and regional plan for controlling animal diseases which act as hurdle in animal production and anathema to livestock and livestock trade in international market.

\section{CONCLUSIONS AND RECOMMENDATIONS}

The study indicated that a vaccination program for diseases like ovine pasteurellosis, pestides petites ruminits, sheep and goat pox vaccine and anthrax was implemented in the study area for the five years period from 2010E.C to 2014. However, the vaccination scheme associated with the occurrence of these diseases was not effective due to lower vaccination coverage in the livestock population of Woreda or lack of vaccines stocks in the vaccine production centre in the country.

Based on the findings the following points were recommended.

$>$ It is essential to improve the vaccination coverage in the area so as to expand the existing vaccination program.

$>$ Inclusion of other livestock diseases vaccines apart from the already existing vaccines available at the Woreda.

$>$ There is a need for continuous surveillance and investigation of different diseases for further improvement of the livestock health apart from the vaccination against different diseases.

$>$ Public awareness creation on the importance of vaccination of livestock should be in place.

\section{ACKNOWLEDGEMENTS}

The authors would like to Acknowledge Alamata Woreda Bureau of Agriculture for provision of the necessary Data during the field investigation. 


\section{REFERENCE}

Mellese N. 2004. Veterinary Management. Presented in the Workshop on PANVAC activities on quality control of vaccine, held on March 14-16, Debrezeit, Ethiopia.

MoA, 2011. Ethiopia animal health. Year book, Ministry of Agriculture, Animal and Plant Health Regulatory Directorate, Addis Ababa, Ethiopia.

National Veterinary Institute, 2004. Hand Book on Handling Usage of Veterinary Vaccine in Ethiopia.

Pastoret, P., Brochier, B., Bloncou, J., Artois, Kieny, M., Lecoco, M.P., Languet, J.P., Chappuis, B \& Desmetter, P. 1996. Development and deliberate release of a vaccine rabies recombinant Virus for the oral vaccination of Foxes against rabies: Veterinary Vaccinology. Epidemiol Infect., 116(3): 235-240.

TBOABR, 1997. Tigray livestock development action program. Main report, Volume 1, Bureau of Agriculture and Recourses, Mekelle, Tigray. pp1-10.

Teshager, A., Belay, D \& Taye, T. 2013. Prevalence of Cattle Diseases and Productive and Reproductive Traits of Cattle in Ilu Aba Bora Zone, SW Ethiopia. Global Veterinaria, 10(5): 614-619.

Waqnwayi, H.M., Kwena, A.V.M., Wkhusama, E.M \& Odera, J. 1997. Storage of Tissue Culture Renderpest in Liquid Nitrogen: Veterinary Vaccinology. Elsvier, Amsterdam, the Netherlands. pp. 539-540. 